\title{
CNC Freze Makinalarında İş Parçasının Talaş Derinliğindeki Değişimin İnterferometrik Temassız Ölçümü
}

\author{
Muammer ZENGIN ${ }^{1}$, H. Selçuk VAROL ${ }^{2}$ \\ 1 Marmara Üniversitesi Fen Bilimleri Enstitüsü Elektrik-Elektronik Mühendisliği \\ 2 Doğuş Üniversitesi Elektronik ve Haberleşme Mühendisliği
}

\section{ÖZET}

İmalat metrolojisinde 1şık kaynağı kullanılarak yapılan ölçümlerde mekanik değerlerin elektronik değerlere çevrilerek bilgisayara aktarılması işlemi üreticiye birçok kolaylık sağlamaktadır. Bunun nedeni ise 1şık kaynağı kullanılarak yapılan ölçüm sistemlerinin hem temassız olması hem de yüksek hassasiyette olması ve anında bilgisayar tarafından işlenebilmesidir. Ayrıca fiziksel olarak ölçüm alınması zor olan iş parçalarının da ölçümü için büyük kolaylık sağlamaktadır. Bu çalışmada, talaşlı üretim endüstrisinde büyük bir yer tutan freze tezgâhlarında düzlem yüzey frezeleme işlemi sırasında talaş derinliğindeki değişim değerini Michelson interferometresi esaslı ölçüm düzeneği ile ölçen bir sistem gerçekleştirilmiştir. Michelson interferometresi ile elde edilen saçakları saymak amacıyla bir elektronik saçak sayıcı devresi tasarlanmıştır. Freze makinasının kontrolünü sağlayan SimCNC yazılımı ile sisteme girilen talaş derinliği değeri, işlem sonucunda lazer ölçüm sisteminin elde ettiği ölçüm değeri ile karşılaştırılıp aralarındaki \% 7'lik farklar yorumlanmıştır.

Anahtar Kelimeler: Freze tezgâhları, Michelson İnterferometresi, Temassız ölçüm

\section{Interferometric Non-Contact Measurement of the Change in Cutting Depth of the Workpiece on CNC Milling Machines}

\begin{abstract}
With respect to measurements made by use of light source in the manufacturing metrology, the conversion of the mechanical values to the electronic ones and then transfer of the results to PC provides a number of advantages for the manufacturer. The reason is that the measurement systems with use of light source are both non-contact and high precise, making instant processing by the computer. Furthermore, it also provides great convenience for measurement of the workpieces, which are physically hard to measure. This study concerns a system to measure the changing value in the cutting depth on basis of Michelson interferometry measuring mechanism during the milling of plane surfaces on the milling machines, which take an important place in the machining industry. An electronic fringe counter is designed in order to count the fringe obtained by the Michelson interferometry. The cutting depth value entered in the system by use of Sim CNC, which controls the milling machine and the measurement value obtained by the laser measurement system as a result of the process were compared and the differences of $7 \%$ between them were interpreted.
\end{abstract}

Keywords: Milling machines, Michelson Interferometry, Non-contact measurement 


\section{GİRIŞ}

Talaşlı imalat metrolojisinde kullanılan ölçüm yöntemlerinin yetersizliği ışık kaynağı kullanılarak yapılan ölçüm yöntemlerine ihtiyacı artırmıştır. Mekanik yapısı zor olan parçalarda ve ulaşılması imkânsız olan yerlerde temassız bir ölçüm alınabilmesi 1şık kaynaklı ölçüm sistemlerinin en büyük avantajlarıdır. Günümüzde gelişen ileri teknoloji ile birlikte mekanik ölçüm yöntemleri artık yerini elektronik ölçüm yöntemlerine bırakmaya başlamıştır. Bu değişim sürecinde birçok elektronik ölçüm metodu geliştirilmeye çalışılmıştır. Bunlardan en önemli olanları ise lazer kullanılarak yapılan ölçüm yöntemleridir. Tek dalga boyunda ve farklı güçlerde elde edilebilmesi lazeri optik ölçüm sistemleri için popüler hale getirmiştir[1,2]. Bu çalışmada talaşlı imalat olan frezeleme işleminde yapılan ölçümler için interferometrik bir sistem geliştirilmesi amaçlanmıştır. Freze takım tezgâhları talaşlı üretim endüstrisinde büyük bir öneme sahiptir. Bu yöntemde, birden fazla eksen kullanımı mümkün olduğu için basit ve karmaşık yüzeylerin işlenmesinde kolaylık sağlar. Freze tezgâhında talaş kaldırma süresince meydana gelen titreşim ve yüzey pürüzlülüğü bu işleme etki eden en önemli faktörlerdir. İşlem esnasında iş parçasına etki eden kesme kuvvetleri aşınma, tezgâh yapısı, iş parçasının türüne bağlı olarak değişir. Bu da sistemde sürekli bir titreşime neden olur. Sistemde meydana gelen bu titreşim yüzey pürüzlülüğünü de büyük bir ölçüde etkilemektedir. Yaptı̆̆gmız bu çalışmada titreşimin minimize edilmesi içinde bir tasarım yapılmıştır. Freze tezgâhlarında çeşitli işlemlere tabi tutulan bir iş parçasının bazı aşamalar sonuncunda istenilen ölçüme ne kadar yaklaştı̆̆ını saptayabilmek için ara ölçümler alınır. İşlem esnasında tüm işlemi durdurup alınan bu ara ölçümler sonucunda işlenen parçanın istenen ölçüme ne kadar yaklaştığı ölçülür, eğer istenilen ölçümü sağlıyor ise işlem sonlandırılır. İşlem sırası boyunca birkaç defa ara ölçüm almak gerekmektedir. Her alınan ara ölçüm için sistem durdurulup işlenen iş parçası makinadan sökülüp mekanik ölçü aletleri kumpas ya da elektronik kumpas ile parçadaki değişim miktarı ölçülür ve istenilen ölçüme ne kadar yakın olduğu belirlenir. Uygulanan bu ölçüm metodu hem zaman kaybına yol açmakta hem de yüksek hassasiyette ölçüm vermemektedir. Freze tezgâhlarında işleme tabi tutulan bir iş parçasının hem zaman kaybetmeden hem de daha yüksek hassasiyetle ölçülebilmesi büyük avantajlar sağlayacaktır. $\mathrm{Bu}$ çalışmada freze tezgâhlarında düzlem yüzey frezeleme işleminde talaş derinliğindeki değişimin temassız bir şekilde ölçülebilmesi için interferometrik bir sistem geliştirilmesi esasına dayanmaktadır. Üzerinde çalışılan bu lazerli temassız ölçüm yöntemi, işleme tabi tutulan iş parçasının herhangi bir temas gerektirmeden kalınlığındaki değişimi 1şık dalga boyu hassasiyetinde ölçme imkânı sağlamaktadır. Kumpas vb. ölçüm aletlerine gerek kalmadan ve iş parçasını makinadan çıkartmadan hatta işlemi durdurmadan parça işleme aşamasındayken her işlem sonucunda ölçüm alabilme imkânı sağlamaktadır. $\mathrm{Bu}$ da işlenen parçaların hammaddelerinin pahalı olması nedeni ile işlenen parçanın yanlış bir ölçüm durumunda kullanılmaz hale gelmesinin önüne geçecektir.

\section{MATERYAL VE YÖNTEM}

\subsection{Frezeleme Yöntemi ile Talaş Kaldırma}

Kesici bir takım yardımıyla iş parçası üzerinden, istenilen ölçü ve toleranslara uygun olarak fazla kısımlarının ana parçadan ayırma işlemine talaş kaldırma denir. Frezeleme işlemi, üzerinde kesici uçlar bulunan kesici takımın kendi ekseni etrafında dönmesi ile iş parçasının bağlı olduğu tablanın $\mathrm{x}, \mathrm{y}, \mathrm{z}$ eksenleri yönlerinde hareket etmesi ile iş parçaları üzerinden talaş kaldırılmasıdır[3,4]. Frezeleme yöntemi ile talaş kaldırma olayını diğer talaşlı imalat yöntemlerinden ayıran temel özellik aynı anda birden fazla kesici ağızla talaş kaldırılmasıdır. Buda frezeleme yönteminin verimliliğinin yüksekliğini gösterir. Frezeleme yöntemi, iş parçasında yapılacak olan imalatın şekline, biçimine ve kullanılan kesici takımın çeşidine göre sınıflandırılır. Bu çalışmada alın frezeleme yöntemi kullanılmıştır.

\subsection{Michelson Interferometresi}

Şekil 1'de gösterilen sistem Albert Abraham Michelson tarafından geliştirilen girişimölçerdir. Bu sistem 1şık demetini iki kısma ayırır ve bu kısımları birleştirerek bir girişim deseni oluşturur. Desendeki şiddet dağılımı demetin iki parçası arasındaki noktadan noktaya yol farkının karakteristiğidir. Böylece, eğer yol uzunluklarının biri değişir ise saçak deseni ekran üzerinde hareket edecek ve yol uzunluklarındaki fark, saçak kayması cinsinden ölçülebilecektir. Bu yöntem hassas mesafe değişimlerinin ölçülmesine olanak sağlamaktadır.

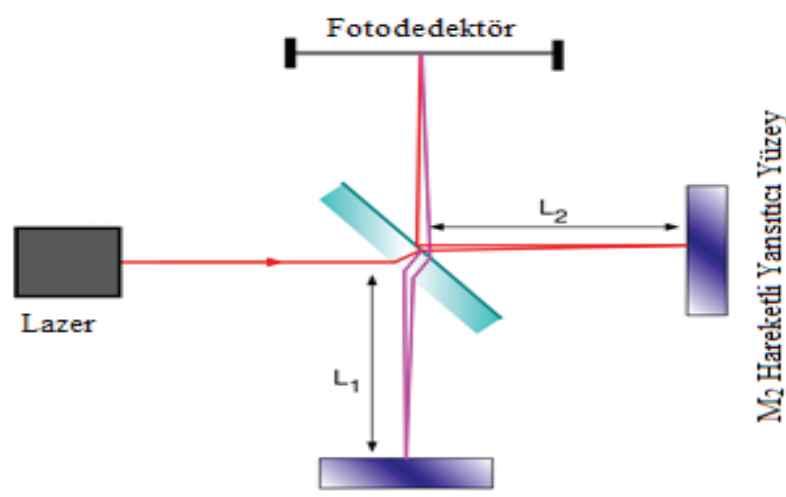

M1 Hareketsiz Yansıtıcı Yüzey

Şekil 1. Michelson Girişimölçeri 
Şekil 1'de gösterilen girişimölçerde, lazer kaynağından çıkan ışın demeti ışın bölücü tarafından aynı şiddete sahip iki ışına ayrıldıktan sonra, hareketsiz yansıtıcı yüzey $M_{1}$ ve hareketli yansitıcı yüzey $M_{2}$ tarafindan yansitılarak fotodedektör üzerinde giriştirilir. İki dalga birleştiğinde dalgalar aynı fazda ise birbirleri üzerine eklenir ve aydınlık saçak meydana getirirler. Dalgaların fazları farklı ise birbirlerini yok ederler. Yol farkı dalga boyunun tam katları ise yap1cı(aydınlık) girişim, dalga boyunun yarım katları ise yıkıcı (karanlık) girişim elde edilecektir.

İki ışık demetinin girişimi neticesinde fotodedektör üzerinde elde edilen dalganın elektrik alanı,

$E=\frac{E_{0}}{2} \sin \left(w t-k 2 l_{2}\right)+\frac{E_{0}}{2} \sin \left(w t-k 2 l_{1}\right)$

şeklinde olacaktır. Bu ifadeyi basitleştirmek için,

$\sin A+\sin B=2 \sin \left(\frac{A+B}{2}\right) \cos \left(\frac{A-\bar{B}}{2}\right)$

özdeşliği kullanılır. Girişim neticesi sonucu oluşan elektrik alan,

$E=E_{0} \cos \left(k\left(l_{2}-l_{1}\right)\right) \sin \left(w t-k\left(l_{2}+l_{1}\right)\right)$

şeklinde yazılabilir.

Bir dalganın şiddeti elektrik alanının karesi ile orantılı olduğundan 1şık şiddeti,

$I \ltimes E^{2}=E_{0}^{2} \cos ^{2}\left(k\left(l_{2}-l_{1}\right)\right) \sin ^{2}\left(w t-k\left(l_{2}+l_{1}\right)\right)$

olarak ifade edilebilir.

Fotodedektör zamana bağlı ortalama 1şık şiddeti ölçtügünden ve $\sin ^{2}\left(w t-k\left(l_{2}-l_{1}\right)\right.$ 'in periyot üzerinden ortalama değeri $1 / 2$ ve dalga sayıs $k=2 \pi / \lambda$ olduğundan fotodedektör tarafından ölçülen 1şık şiddeti,

$I=I_{0} \cos ^{2}\left(\frac{2 \pi}{\lambda}\left(l_{2}-l_{1}\right)\right)$

şeklinde olacaktır.

$$
\begin{aligned}
& \frac{2 \pi}{\lambda}\left(l_{2}-l_{1}\right)=N \pi \text { olduğunda aydınlık (II.6) } \\
& \frac{2 \pi}{\lambda}\left(l_{2}-l_{1}\right)=(N+1 / 2) \pi \text { olduğunda da karanlıklar sa- }
\end{aligned}
$$
çak oluşur. (II.7)

Burada $N= \pm 1, \pm 2, \pm 3, \ldots$, fotodedektör üzerinden geçen aydınlık ve karanlık saçakların sayısıdır. Yol farkı $\Delta x=l_{2}-l_{1}$ şeklinde yazılır ise fotodedektör önünden akan aydınlık saçak sayısı
$N=\frac{2 \Delta x}{\lambda}$

olup bir sayma devresi ile fotodedektör önünden geçen aydınlık saçaklar sayıldığında $\Delta x$ yer değiştirmesi,

$\Delta \mathrm{x}=\frac{\mathrm{N} \lambda}{2}$

şeklinde hesaplanabilir. N uygun bir sistemle saydırıldığında ve lazer ışınının dalga boyu bilindiğinde talaş derinliğindeki değişim ölçülebilecektir[5,6,7].

\subsection{Deney Düzeneği}

Yapılan bu çalışmada freze tezgâhlarında düzlem yüzey frezeleme işlemi sırasında talaş derinliğindeki değişimin Michelson interferometresi esaslı bir sistem geliştirilerek ölçülmesi için bir deney düzeneği tasarlanması amaçlanmıştır. Tasarlanan deney düzeneğinde Marmara Üniversitesi Teknoloji Fakültesi Kontrol Laboratuvarında mevcut halde bulunan freze makinası kullanılmıştır. Kullanılan Terco marka makine dik işleme (freze) özelliğine sahip bir NC takım tezgâhıdır. Tezgâhın imal tarihi 1970'li yılların sonlarına denk gelmektedir. 3 eksenli dik işleme özelliğine sahip olan Terco yüzey işleme tezgâhının ürün işleme hacmi ise $576000 \mathrm{~mm}^{3}$ (X x Y x Z - 180 mm x 80 mm x 40 mm)'tür. Deney malzemesi olarak ise endüstrinin birçok alanında yaygın olarak kullanılan olan AISI 303 östenik paslanmaz çelik numuneler kullanılmıştır. Malzemelerin boyutları konusunda belirli bir standart da sabit kalınmamış farklı boyutlarda malzemeler kullanılmıştır. Kullanılan numunenin kimyasal kompozisyonu Tablo 1'de verilmiştir.

Tablo 1. Kullanılan deney malzemesinin kimyasal kompozisyonu (\% Ağırlık)

\begin{tabular}{llllllll}
\hline $\mathbf{C}$ & $\mathrm{Mn}$ & $\mathrm{Si}$ & $\mathbf{C r}$ & $\mathrm{Ni}$ & $\mathbf{P}$ & $\mathbf{S}$ & $\mathrm{Mo}$ \\
\hline 0.085 & 2 & $0.5-1$ & $18-20$ & $8-10.5$ & 0.027 & 0.225 & 0.25 \\
$\mathbf{A l}$ & $\mathbf{C u}$ & $\mathbf{N b}$ & $\mathbf{T i}$ & $\mathbf{V}$ & $\mathbf{W}$ & $\mathbf{F e}$ & $\mathbf{C o}$ \\
0.008 & 0.12 & 0.002 & 0.001 & 0.045 & 0.005 & 61.7 & 0.065 \\
\hline
\end{tabular}

Kullanılan kontrol programından (SimCNC) Tezgâh Ayarları arayüzünde tezgâhın, boyut, hız, darbe/mm ve takım çapı bilgileri girilerek frezeleme işlemi yapılmıştır. Tezgâh ayarları arayüzünde bulunan bölümler Şekil 2'de gösterilmiştir. 


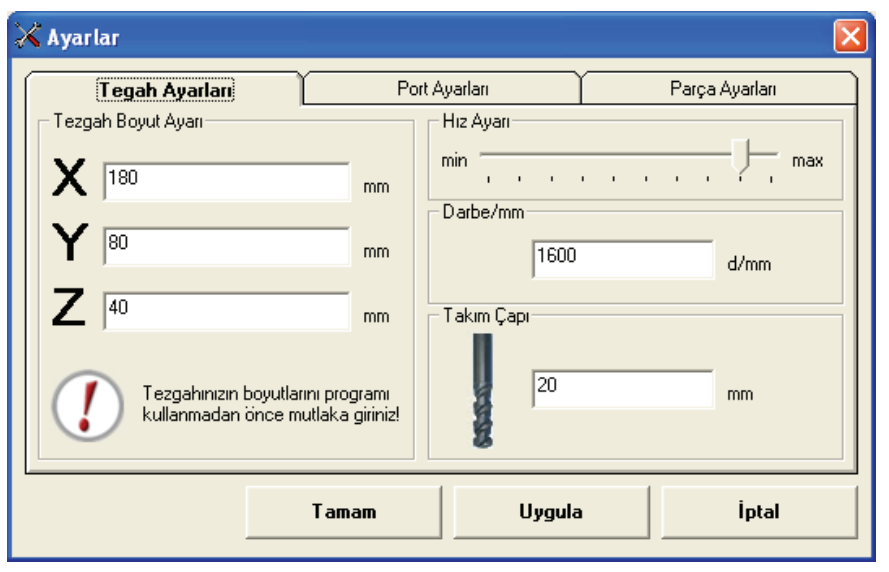

Şekil 2. Tezgâh Ayarları Arayüzü

Lazer kaynağı olarak da 632,8 nm dalga boyunda, $5 \mathrm{mw}$ gücünde polarize Helyum-Neon lazer kullanılmıştır. HeNe lazerden çıkan ışın çapı ince kenarlı bir mercek yardımı ile odaklanarak ışın bölücü üzerine düşürülür. Işın bölücü tarafından iki eş parçaya ayrılan ışınlardan bir tanesi sabit aynaya yönlendirilirken diğer ışın ise ölçümü alınacak iş parçasının üzerine yönlendirilir. Sabit ayna ve iş parçası üzerinden geri yansıyan 1şınlar ışın bölücü üzerinde birleşerek bir girişim deseni oluşturur. Burada 1şın bölücü ışınları birleştirme işlemini de üstlenmiş olur. Birleşen bu ışınların oluşturduğu girişim deseni fotodedektör üzerine düşürülerek algılanır. Şekil 3'de elde edilen girişim deseni ve deney düzeneği görülmektedir. Ancak oluşan bu girişim deseni çıplak gözle görülebilmesi için genişletme işlevini görecek bir mercek ve titreşim giderici sünger ve kauçuk kullanılmıştır. Deney düzeneğinin belirli bölgelerine yerleştirilen titreşim önleyici sünger ve kauçuklar ile titreşim önlenerek daha sağlıklı görüntü almak mümkün olmuştur.

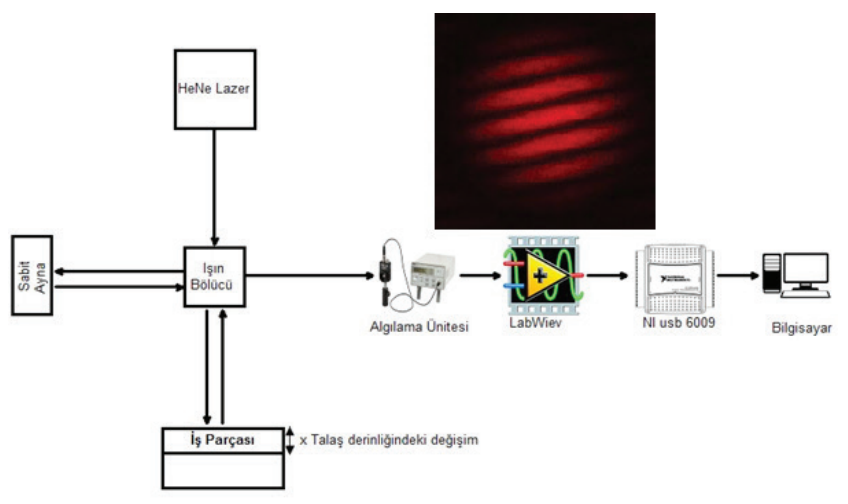

Şekil 3. Tasarlanan Deney Düzeneği
Fotodedektör tarafından algılanan elektriksel sinyal işlemsel kuvvetlendiriciden geçtikten sonra 74C14 Schmitt Trigger entegresi kullanılarak 0-5 V dijital sinyale çevrilmiştir. Üretilmiş olan 0-5 V sinyali sayabilmek için de 74C926 sayıcı entegresi kullanılmıştır. 74C926 sayıcı entegresinden çıkan 16 bitlik ikili düzendeki sayılar 4 dijit gösterge ekranına aktarılmıştır. Ayrıca sayıcı entegresinden elde edilen sayılar bilgisayara aktarıp işlem yapabilmek amacıyla NI USB 6009 veri toplama kartı ile bağlantılanmıştır. Kullanılan veri toplama kartı ile elde edilen sayıcı değeri bilgisayara aktarılmıştır. Bilgisayara aktarılan bu verileri işleyebilmek için Labview programı kullanılmıştır. Labview programında tasarlanan talaş derinliğindeki değişimi hesaplama ara yüzü sayıcıdan veri toplama kartı ile bilgisayara aktarılan verileri kullanarak VI.1 nolu formül vasıtasıyla talaş derinliğindeki değişim hesaplanmıştır. Şekil 4'de bu deney düzeneği için tasarlanan elektronik sayıcı devresinin şeması görülmekte$\operatorname{dir}[8]$.

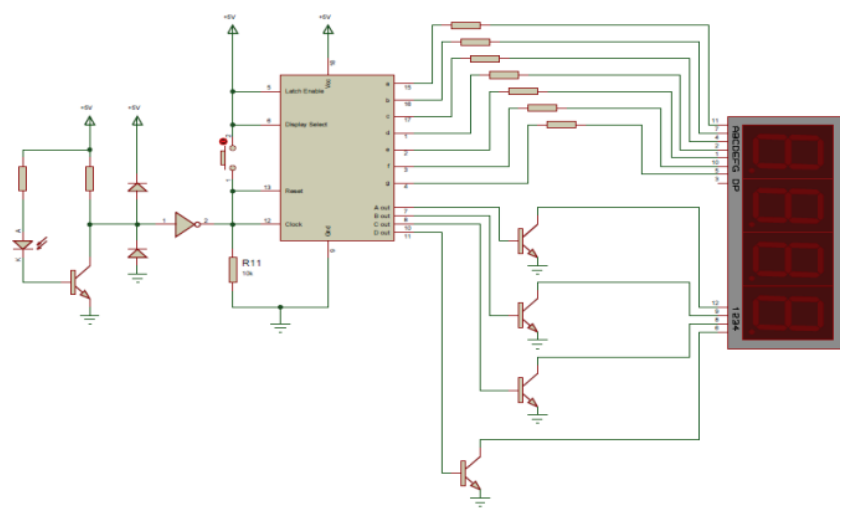

Şekil 4. Elektronik Sayıcı Devresi

\section{SONUÇ}

Talaşlı üretim endüstrisinin en önemli öğelerinden biri olan frezeleme işlemlerinde kullanılan mevcut ölçüm yöntemlerine alternatif olacak olan bu ölçüm sistemi diğer ölçüm yöntemlerine oranla daha hassas bir sonuç ortaya koymaktadır. Mevcut ölçüm yöntemlerinin yetersiz kaldığı yerlerde daha kullanışlı ve hassas bir ölçüm sistemi geliştirmek amaçlı tasarlanan bu sistemin ana dayanağı Michelson interferometresi'dir. $\mathrm{Bu}$ yöntem ile tasarlanan deney düzeneğinde, işleme tabi tutulacak olan iş parçasına freze makinasının kontrol yazılımı tarafından verilen talaş derinliğinden sonra metal plakada meydana gelen incelme oluşan saçak demetinin hareket etmesini sağlamıştır. Bu hareket kullanılarak saçaklar elektronik olarak sayılmış ve verilen talaş derinliğindeki değişim 1şık dalga boyu hassasiyetinde ölçülmüştür. 
Tablo-2 incelendiğinde freze makinasını kontrol eden SimCNC yazılımı kullanılarak verilen talaş derinliği ile lazer ölçüm sisteminin elde ettiği veriler görülmektedir.

Tablo 2. Deney Ölçüm Değerleri ve SimCNC Yazılım Değerleri

\begin{tabular}{cc}
\hline $\begin{array}{c}\text { Talaş Derinliği } \\
\text { SimCNC } \\
(\mathrm{mm})\end{array}$ & $\begin{array}{c}\text { Lazer Ölçüm } \\
\text { Sistemi } \\
(\mathrm{mm})\end{array}$ \\
\hline 0,3 & 0,2958 \\
0,4 & 0,3534 \\
0,5 & 0,4508 \\
0,6 & 0,5627 \\
\hline
\end{tabular}

SimCNC yazılımı Microsoft Visual Basic görsel programlama dilinde oluşturulan $\mathrm{CNC}$ tezgâhının işleyişi ve kumanda edilmesi amacıyla tasarlanmış bir kontrol yazılımıdır[9]. Kullandığımız freze tezgâhı bu yazılım ile kontrolü yapılmıştır. SimCNC yazılımına 4 adet talaş derinliği değeri girilerek malzemeden talaş kaldırılmıştır. Lazer ölçüm sistemi ile elde edilen neticeler SimCNC yazılımına verilen talaş derinliği neticeleri ile karşılaştırılmıştır. Kullanılan SimCNC tarafından verilen değerlere oldukça yakın değerler elde edilmiştir. Bu noktada meydana gelen hataların en önemli ve başlıca sebepleri titreşim ve yüzey pürüzlülüğü olmuş$\operatorname{tur}[10]$. Yapılan kalibrasyon ile sisteme son şekli verilmiştir. Tasarlanan lazer ölçüm sistemi Şekil 5'de görülmektedir.

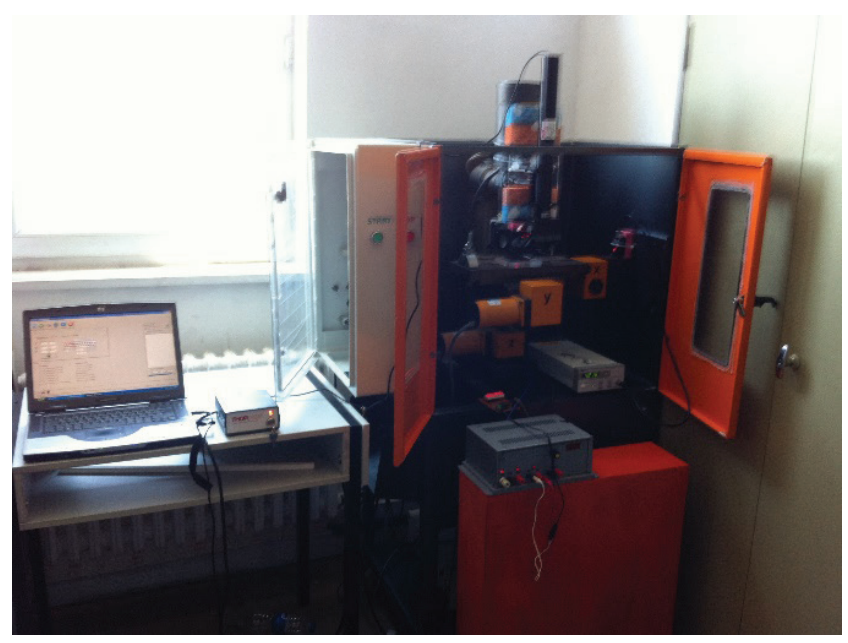

Şekil 5. CNC Tezgâhına Monte Edilmiş Lazer Ölçüm Sistemi

Talaş derinliğindeki değişimi hesaplayabilmek için III.1 nolu formül kullanılmıştır. $\mathrm{x}_{\text {olçülen }}=\mathrm{N} \frac{\lambda}{2}$

Alınan ölçüm sonuçları ile SimCNC yazılımı sonuçlar kıyaslanarak ölçmede yapılan hata oranları mutlak hata eşitliği ile $\% 7,2$ olarak bulunmuştur.

$$
\begin{aligned}
& \Delta X=X_{\text {ollcülen }}-X_{\text {simCNC }} \\
& \beta=\frac{X_{\text {olçalen }}-X_{\text {simcNc }}}{X_{\text {simcNe }}}
\end{aligned}
$$

\section{DEĞERLENDİRME}

Freze makinalarında işlenen iş parçasının talaş derinliğindeki değişimin ölçülmesine bir alternatif oluşturacak olan bu çalışmanın ana dayanağ 1 Michelson girişimölçeridir. Gerçekleştirilen bu sistemde Michelson interferometresi kullanılarak freze makinalarında işlenen iş parçasının talaş derinliğindeki değişim ölçülmektedir. İnterferometrik ölçüm yönteminin sağladığı yüksek hassasiyette sonuç elde edebilme imkânında bazı olumsuzlukları da ortaya çıkarmaktadır. Bu olumsuzluklar titreşim ve yüzey pürüzlülüğüdür, elde edilen girişim deseninde diş etkenlere bağlı titreşimlerin oluşması oluşturulan ölçme sistemine büyük oranda etki etmektedir. Ortaya çıkan bu durumlar kullanılan yöntemlerle ile minimuma indirilmiştir. Dış etkenlere bağlı titreşimi ve titreşimin etkilediği yüzey pürüzlülüğünü en aza indirebilmek için, freze makinasının yer ile temas eden plastik ayaklar bagalit ayaklar ile değiştirilmiş ve sistemin belirli noktalarına titreşim sönümleyici kauçuk-sünger kar1şımı dolgular yapılmıştır. Yapılan bu işlemler sonucunda titreşim büyük oranda azaltılmış ve girişim desen görüntüsü çıplak gözle net bir şekilde görünmüştür. Fotodedektör tarafindan kolayca algılanan girişim deseni sonucu saçak sayma işlemi geliştirilen elektronik saçak sayma sistemi ile başarılı bir şekilde gerçekleştirilmiştir. Alınan yukarıdaki önlemler neticesinde SimCNC yazılımı ile sisteme girilen talaş derinliği değerleri ve lazer sistemi ile elde edilen ölçüm değeri arasında \% 7'lik bir fark oluşmuştur. Bu da lazer ölçüm sisteminin CNC tezgâhlarında talaş derinliği değişiminin temassız ölçümünde bir alternatif olarak kullanılabileceği neticesini vermektedir.

\section{TEŞEKKÜR}

Bu çalışma FEN-C-YLP-141014-0350 numaralı Marmara Üniversitesi BABKO Lisansüstü Tez projesi kapsamında desteklenmiştir. 


\section{KAYNAKLAR}

[1] Yandayan, T. İmalat Metrolojisinde Lazer Kullanarak Yap1lan Ölçme Teknikleri, 2. Ulusal Ölçüm Bilim Kongresi, 2324 Ekim 1997, Eskişehir, Türkiye.

[2] Gasvik, K. J. (2003). Optical metrology. John Wiley \& Sons.

[3] Akkurt, M. (2000). Talaş kaldırma yöntemleri ve takım tezgâhları. Birsen Yayınevi.

[4] İpekçioğlu, N. (1984). Frezecilik. Milli Eğitim Basımevi.

[5] Serway, R. A., Beichner, R. J., Jewett, J. W., \& Çolakoğlu, K. (2002). Fen ve mühendislik için fizik: Elektrik ve manyetizma-Işı ve optik. Palme Yayıncılık.

[6] Guoxiong, Z. H. A. N. G. (2008). Development orientations of coordinate measuring techniques. Infrared and Laser
Engineering.

[7] Wilson, J., Hawkes, J. F. B., \& Okur, İ. (2000). Optoelektronik. Değişim Yayınları.

[8] Pastacı, H. (2000). Elektrik ve elektronik ölçmeleri. Yıldız Teknik Üniversitesi.

[9] Uyanık, A. S, ŞİMŞEK, AYTAN, İ. N, ONAT, M., \& ERDAL, H. 3 Eksenli Yüzey İşleme Tezgâhının Bilgisayar ile Kontrolü (Computer Aided Control of 3-Axis Surface Processing Machine.

[10] Ay, M. (2003). "CNC freze tezgahında frezeleme esnasında olusan kesme kuvvetlerinin ve titresimlerin yuzey puruzluluğune etkilerinin incelenmesi”, Doktora Tezi, Sakarya Üniversitesi Fen Bilimleri Enstitüsü, Sakarya. 